\title{
Stable K isotope characteristics at mid-ocean ridge hydrothermal vents and their implications for the modern and ancient $K$ cycle
}

\author{
XIN-YANG CHEN ${ }^{1}$, BRIAN BEARD ${ }^{2}$, MASON \\ NEUMAN $^{2}$, MARIA FAHNESTOCK ${ }^{3}$, JULIA \\ BRYCE $^{3}$, CLARK JOHNSON ${ }^{2}$, XIN-YUAN ZHENG ${ }^{1}$ \\ ${ }^{1}$ Department of Earth and Environmental Sciences, University \\ of Minnesota-Twin Cities, Minneapolis MN 55455, \\ USA (xinychen@uw.edu, zhengxy@umn.edu) \\ ${ }^{2}$ Department of Geoscience, University of Wisconsin- \\ Madison, Madison WI 53706, USA \\ ${ }^{3}$ Department of Earth Sciences, University of New \\ Hampshire, Durham NH 03824, USA
}

The potassium $(\mathrm{K})$ cycle is related to silicate weathering and possible reverse weathering more directly than any other major cations in the ocean because $\mathrm{K}$ is mostly concentrated in silicates. The $\mathrm{K}$ cycle, therefore, has a significant bearing on Earth's climate over geological timescales. Stable K isotopes $\left({ }^{41} \mathrm{~K} /{ }^{39} \mathrm{~K}\right.$ or $\left.\delta^{41} \mathrm{~K}\right)$ provide a novel proxy for $\mathrm{K}$ cycling $[1,2]$, but a major unknown on this new isotope system is the influence of hydrothermal alteration that is known to be a major $\mathrm{K}$ sink at low temperatures and a major $\mathrm{K}$ source at high temperatures in the ocean.

Here we report $\delta^{41} \mathrm{~K}$ analyses of mid-ocean ridge (MOR) hydrothermal fluids collected from the Gorda Ridge and East Pacific Rise (EPR). Measured $\delta^{41} \mathrm{~K}$ ranges between the values of seawater and basalt. These variations are largely controlled by fluid-basalt interactions, although small $\mathrm{K}$ isotope fracitonation during phase separation may exist. Time-series samples from EPR show that fluid $\delta^{41} \mathrm{~K}$ can approach the seawater value immediately after a volcanic eruption that perturbed fluid chemistry, and return to pre-eruption values within $\sim 2$ years, providing an estimation for the timescale of water-rock interaction in the local vent system.

Fluid $\delta^{41} \mathrm{~K}-{ }^{87} \mathrm{Sr} /{ }^{86} \mathrm{Sr}$ systematics quantifies $\sim 0.2-0.6 \%$ K isotope fractionation between basalt and fluid, with altered basalts having higher $\delta^{41} \mathrm{~K}$ values. Our results preclude hydrothermal alteration as the cause for the higher $\delta^{41} \mathrm{~K}$ value of seawater relative to the Bulk Silicate Earth, highlighting the potential significance of authigenic clay formation in the global K cycle. Applying K isotope fractionation constrained here to published ophiolite data [3] implies a considerably lower $\delta^{41} \mathrm{~K}$ value in the Ordovician seawater, possibly reflecting enhanced authigenic clay formation at that time.

[1] Li et al., PNAS, 2019; [2] Santiago Ramos et al., GCA, 2018; [3] Parendo et al., PNAS, 2017 